\title{
Anomalous origin of the left coronary artery from the pulmonary artery in an adult
}

\author{
THOMAS VESTERLUND, „, POUL ERIK BLOCH THOMSEN,† OLE KROMAN HANSEN $\ddagger$ \\ From the ${ }^{2}$ Department of Cardiology, Aalborg Hospital, Aalborg; and the Departments of $†$ Cardiology and $¥ T$ Thoracic \\ Surgery, Aarhus Konmounehospital, Aarhus, Denmark
}

SUMMARY Anomalous origin of the left coronary artery from the pulmonary artery is a rare, almost universally fatal form of congenital heart disease. A case was diagnosed in a 19 year old woman who had exercise induced syncope and ST segment displacement during exercise stress testing. The anomaly was successfully treated with ligation of the anomalous left coronary artery combined with saphenous vein grafting.

Young adults with exercise induced syncope should be examined by exercise stress testing, and if it induces ST segment displacement coronary angiography should be undertaken.

Anomalous origin of the left coronary artery from the pulmonary artery was first described by Abrikossoff in $1911 . .^{1}$ About $80-90 \%$ of the reported cases of this abnormality are of the infantile type, and these patients develop congestive heart failure and die in infancy. About $15 \%$ of cases survive beyond infancy. Some of these patients die suddenly after exertion. ${ }^{2-4}$ We report an example of this condition in an adult, who underwent successful surgical treatment.

\section{Case report}

A 19 year old woman, who as a child participated in physical exercise without any symptoms, had been referred to the local hospital when 17 years old because of an episode of exercise induced syncope. Since the electrocardiogram was normal, no cardiac murmur was heard, and no neurological abnormalities were found she was discharged. Two years later she had a further episode of syncope during gymnastic exercise. Cardiac arrest occurred, and resuscitation was started during transportation to the local hospital. The electrocardiogram showed ventricular fibrillation. Direct current cardioversion resulted in sinus rhythm, and she was referred to our department for further examination.

On examination, there were some deficiences in her memory, her blood pressure was $120 / 70 \mathrm{~mm} \mathrm{Hg}$, and

Requests for reprints to Dr Thomas Vesterlund, Department of Cardiology, Aalborg Hospital, DK-9100 Aalborg, Denmark.

Accepted for publication 26 November 1984 cardiac auscultation detected no cardiac murmurs and normal first and second heart sounds. The electrocardiogram showed a biphasic $T$ wave in lead I but no other abnormalities. The chest radiograph suggested some left ventricular enlargement in the lateral view, but the total heart size was normal. Echocardiographic examination was normal. Exercise stress testing showed a $0.3 \mathrm{mV}$ depression of the ST segment in lead CM5 but produced no chest pain. The patient was referred for right heart catheterisation and intracardiac electrography. These examinations showed no signs of left to right shunt, and no inducible ventricular tachycardia or ventricular fibrillation was recorded during electrophysiological studies. Myocardial perfusion scintigraphy with thallium-201 showed decreased activity in the anteroapical region. We therefore decided to perform coronary angiography. There was no evidence of aortic stenosis, and the pressures in the left ventricle were normal (100/8 $\mathrm{mm} \mathrm{Hg}$ ). Left ventriculography showed a normal contraction pattern, an ejection fraction of 0.71 , no signs of mitral regurgitation, and no left coronary artery arising from the aorta. The right coronary orifice was found to be very wide and when injected with contrast was dilated and tortuous with many collateral channels through which the contrast passed to the left coronary artery and finally drained retrog radely into the pulmonary artery (Figure $a$ ).

At operation the right coronary artery was dilated. The left anterior descending artery was small with an internal diameter of $2 \mathrm{~mm}$. The left anterior descending and the circumflex arteries were in the normal 

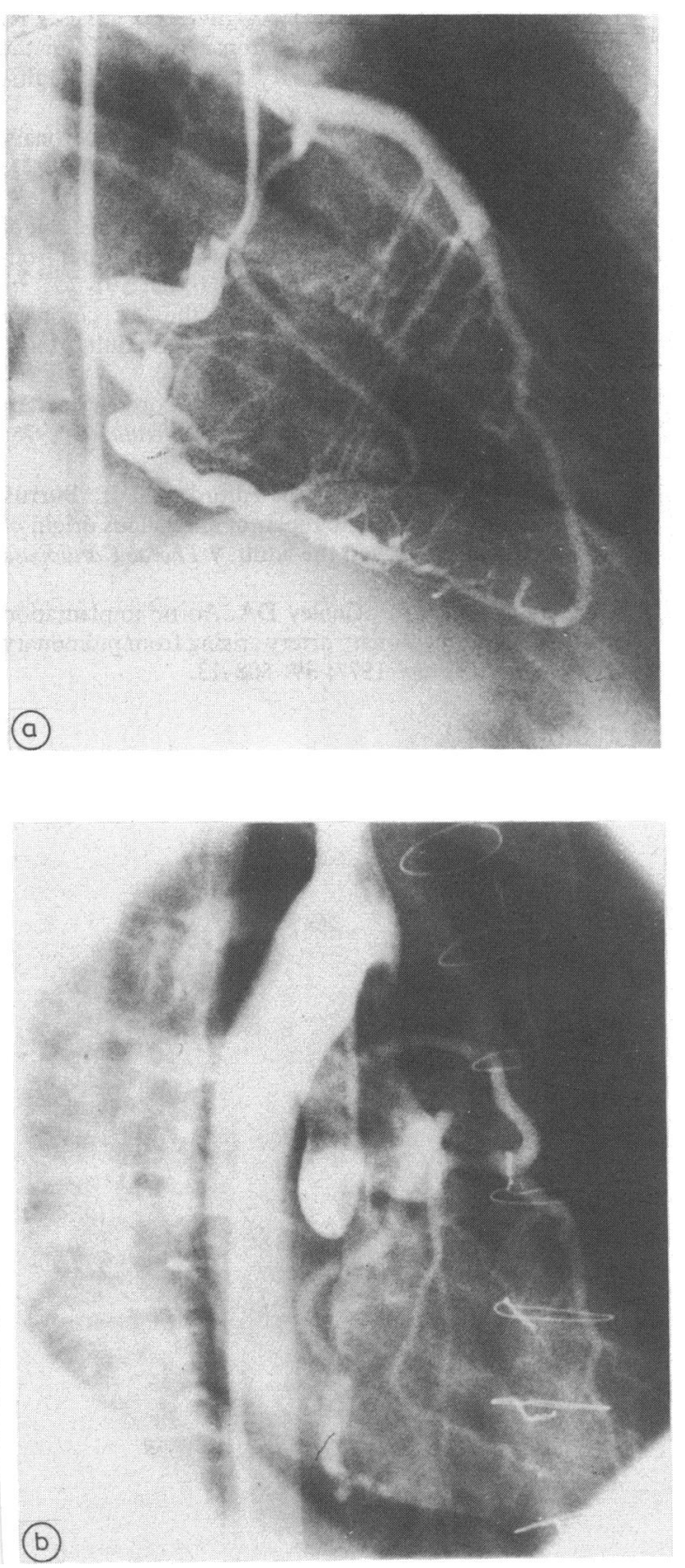

Figure (a) Preoperative coromary angiogram in the right anterior oblique projection with contrast injection into the right coronary artery showing retrograde filling of the left coronary artery and the circuonflex artery. There is weak contrast filling of the pribmonary artery. (b) Postoperative angiogram in the right anterior oblique projection with contrast injection into the aorta showing contrast filling of the venous grafi and the left coronary, the circuonflex, and the right coronary anteries. There are no signs of contrast passing from the right to the left coronary arteries. anatomical position, but the left main coronary artery originated from the posterior wall of the pulmonary artery. After the left main coronary artery had been dissected, it was ligated close to the pulmonary artery and divided. A piece of reversed saphenous vein was inserted between the left main coronary artery and the aorta, using an end to side suture for the peripheral anastomoses. The postoperative course was uneventful, and the electrocardiogram was unchanged.

Five months later repeat angiography showed that the right coronary artery was dilated and tortuous but there was no contrast filling of the left coronary arteries. When contrast was injected into the aorta we found a patent venous graft with contrast filling of the left anterior descending artery, the septal branches, and the circumflex artery (Figure $b$ ). The electrocardiogram still showed a biphasic $T$ wave in lead I but no other abnormalities. The chest radiograph was normal. Exercise stress testing showed a $0.2 \mathrm{mV}$ depression of the ST segment in lead CMS of the electrocardiogram. The patient had to stop exercise because of exhaustion.

\section{Discussion}

Anomalous origin of the left coronary artery from the pulmonary artery is the most common clinically severe congenital anomaly affecting the coronary system. Nevertheless, it is a rare defect occurring in 0.5 of the total group of congenital heart disease. According to Keith it occurs in one of every 300000 live births. ${ }^{5}$ Retrograde blood flow in the left coronary artery is present in probably all patients who survive childhood. ${ }^{6}$

Surgical treatment of this anomaly has included ligation of the anomalous left coronary artery, ${ }^{7}$ ligation of the anomalous left coronary artery combined with saphenous vein grafting from the aorta to the left coronary artery, ${ }^{89}$ and reimplantation of the anomalous left coronary artery in the aorta. ${ }^{10}$ Our patient was treated with ligation of the anomalous left coronary artery combined with saphenous vein grafting from the aorta to the left coronary artery.

This case is interesting because of the lack of abnormalities found at physical examination and especially because of her resting electrocardiogram, in which we would have expected to find $Q$ waves (indicating previous anterolateral or anteroseptal myocardial infarction) or alterations in the ST segments and the $T$ waves, which have been reported by others. ${ }^{347}$ As reported by others we found an abnormal ischaemic response in the electrocardiogram during preoperative exercise stress testing. ${ }^{310}$

The present case illustrates the importance of performing exercise stress testing in young adults with exercise induced syncope, even if there are no signs of 
cardiac disease. It also emphasises the importance of performing coronary angiography in these patients when ST segment displacement is found at exercise stress testing.

\section{References}

1 Abrikossoff A. Aneurysma des linken Herzventrikels mit abnormer Abgangstelle der linken Koronararterie von der Pulmonalis bei einem fünfmonatlichen Kinde. Virchows Arch [Pathol Anat] 1911; 203: 413-20.

2 Sabiston DC Jr, Pelargonio S, Taussig HB. Myocardial infarction in infancy: the surgical management of a complication of congenital origin of the left coronary artery from the pulmonary artery. $\mathcal{F}$ Thorac Cardiovasc Sung 1960 ; 40: 321-36.

3 Moodie DS, Fyfe D, Gill GC, et al. Anomalous origin of the left coronary artery from the pulmonary artery (Bland-White-Garland syndrome) in adult patients: long-term follow-up after surgery. Am Heart $\mathcal{F}$ 1983; 106: 381-8.
4 Ihekwaba FN, Davidson KG, Ogilvie B, Caves PK. Anomalous origin of the left coronary artery from the pulmonary artery with coronary artery steal in adults. Thorax 1976; 31: 337-45.

5 Keith JD. The anomalous origin of the left coronary artery from the pulmonary artery. Br Heart $\mathcal{f} 1959$; 21: $149-61$.

6 Sabiston DC Jr, Neill CA, Taussig HB. The direction of blood flow in anomalous left coronary artery arising from the pulmonary artery. Circulation 1960; 22: 591-7.

7 Roche AHG. Anomalous origin of the left coronary artery from the pulmonary artery in the adult. $A m \mathcal{F}$ Cardiol 1967; 20: 561-5.

8 Askenazi J, Nadas AS. Anomalous left coronary artery originating from the pulmonary artery. Circulation 1975; 51: 976-87.

9 Thomas CS Jr, Campbell WB, Alford WC Jr, Burrus GR, Stoney WS. Complete repair of anomalous origin of the left coronary artery in the adult. F Thorac Cardiovasc Surg 1973; 66: 439-46.

10 Grace RR, Angelini P, Cooley DA. Aortic implantation of anomalous left coronary artery arising from pulmonary artery. Am f Cardiol 1977; 39: 608-13. 